\title{
PENGARUH DANA PENGEMBANGAN USAHA AGRIBISNIS PERDESAAN TERHADAP PENDAPATAN ANGGOTA KELOMPOK PADA GAPOKATAN DI KELURAN REJOSARI KECAMATAN TENAYAN RAYA
}

\author{
${ }^{1)}$ Latifa Siswati, Rini Nizar, Mufti. \\ 1) Staff Pengajar Fakultas Pertanian Universitas Lancang Kuning \\ Email : latifasiswati@yahoo.com
}

\begin{abstract}
ABSTRAK
Penelitian ini mengetahui Pengaruh dana pengembangan usaha agribisnis perdesaan terhadap anggota kelompok pada Gapoktan di Kelurahan Rejosari Kecamatan Tenayan Raya,tujan program ini untuk mempercepat tumbuh dan berkembangnya usaha agribisnis dengan sasaran untuk mengurangi kemiskinan.

Metode penelitian adalah survey, sampel diambil secara purposiv yaitu disengaja anggota kelompok petani yang mendapat dana PUAP di Kelurahan Rejosari Kecamatan Kulim. Penelitian ini dapat memberikan gambaran bagaimana pengaruh dana PUAP untuk meningkatkan pendapatan dan kesejahteraan anggota kelompok tani yang tergabung dalam Gapoktan.

Hasil penelitian menumukan jenis usaha yang didanai adalah ushatani,ternak kambing,ternak ayam,dagang,usaha kue. Telah terjadi peningkatan pendapatan sebesar Rp 636,364,- per bulan.
\end{abstract}

Keywords : PUAP, Gapoktan, pendapatan .

\section{PENDAHULAN}

Permasalahan mendasar yang dihadapi petani adalah kurangnya akses kepada sumber permodalan, pasar dan teknologi, serta organisasi tani yang masih lemah. Akibatnya usaha pertanian di Indonesia khususnya Kecamatan Tenayan Raya sampai saat ini masih banyak didominasi oleh usaha dengan: skala kecil, modal yang terbatas, penggunaan teknologi yang masih sederhana, sangat dipengaruhi oleh musim, serta wilayah pasarnya lokal. Untuk mengatasi permasahan sumber modal pemerintah sudah menetapkan program Pengembangan Usaha Agribisnis Perdesaan (PUAP) semenjak tahun 2008 ,tujuan program ini untuk mempercepat tumbuh dan berkembangnya usaha agribisnis dengan sasaran mengurangi kemiskinan dan pengangguran di perdesaan yang akhirnya meningkatkan pendapatan masyarakat.

Upaya yang dilakukan untuk penanggulangan permasalahan tersebut, Kementrian Pertanian telah melaksanakan program Pengembangan Usaha Agribisnis Perdesaan (PUAP) yang secara terintegrasi dengan Program Nasional Pemberdayaan Masyarakat (PNPM) Mandiri. Program PUAP merupakan bentuk fasilitasi bantuan modal usaha untuk petani anggota, baik petani pemilik, petani

10 Pengaruh Dana Pengembangan Usaha Agribisnis Perdesaan Terhadap Pendapatan Anggota Kelompok Pada Gapokatan Di Keluran Rejosari Kecamatan tenayan raya 
penggarap, buruh tani maupun rumah tangga tani yang dikoordinasikan oleh Gabungan Kelompok Tani (Pedoman Umum PUAP, 2010).

Kelurahan Rejosari Kecamatan Tenayan Raya Pekanbaru merupakan salah satu yang mendapat dana PUAP pada tahun 2010. Untuk mengetahui perkembangan pelaksanaan, penyaluran, dan pemanfaatan dana BLM-PUAP diperlukan monitoring, evaluasi, dan pelaporan secara sistematik, berjenjang, terukur, transparan, dan dapat dipertanggung jawabkan (Departemen Pertanian, 2008).

Dana tersebut digunakan untuk membiayai kegiatan produktif seperti budidaya tanaman pangan, hortikultura,kegiatan non budidaya terkait dengan komditas pertanian seperti industri rumah tangga pertanian ,pemasaran hasil pertanian dan usaha lain berbasis pertanian. Pemberian dana PUAP dapat meningkatkan pendapatan petani ,peningkatan pendapatan tersebut menjadi tolak ukur keberhasilan dana PUAP. Setiap kegiatan memerlukan penilaian atau evaluasi. Evaluasi program PUAP bertujuan untuk menyediakan data dan informasi serta rekomendasi bagi pengambil kebijakan (decision maker) untuk memutuskan apakah akan melanjutkan, memperbaiki atau menghentikan program tersebut. Berdasarkan pengamatan bahwa pemberian dana PUAP dapat membantu modal usaha anggota GAPOKTAN.

Permasalahan dalam penelitian ini semenjak digulirkan dana PUAP di Kelurahan Rejosari Kecamatan Tenayan Raya belum dilakukan bagaimana pengaruh dana bantuan terhadap pendapatan kelompok tani . dana ini dapat dimanfaatkan sebagai modal usaha agribisnis dalam bentuk usaha apa?

Tujuan penelitian ini adalah:

1. Mengetahui jenis usaha

2. Pendapatan bersih dari usaha sumber dana PUAP

3. Pengaruh pemberian dana PUAP terhadap anggota kelompok

\section{METODE PENELITIAN}

Penelitian dilaksanakan di Keluran Rejosari Kecamatan Tenayan Raya , Selama 4 bulan .Mulai bulan September sampai Desember 2015.

Penelitian ini dilakukan dengan metode survey yang menjadi subjek penelitian adalah anggota Gapoktan yang mendapat dana PUAP di Kelurahan Rejosari Kecamatan Tenayan Raya.Data yang diambil terdiri dari data primer dan 
sekunder. Data primer di peroleh langsung dari anggota Gapoktan. Data sekunder di peroleh dari instansi terkait dan dinas Pertanian kota Pekanbaru.

Pengambilan sampel dilakukan dengan purposive sampling dimana sampel anggota kelompok tani yang tergabung dalam GAPOKTAN di kelurahan Rejosari Kecamatan Tenayan Raya.

Pada penelitian ini teknik pengambilan data dilakukan melalui;a. wawancara langsung kepada anggota kelompok tani mengunakan kuisioner, b. observasi yaitu pengumpulan data langsung kepada objek penelitian, c. dokumentasi yaitu mengumpulkan data dengan cara meneliti dokumen/catatan/arsip. Yang dimiliki Gapoktan dan pengurus.

Analisis data dilakukan dalam mencapai tujan penelitian ini adalah analisis deskriptif kualitatif.analisis data ini dilakukan pengumpulan data secara langsung, untuk menjawab tujuan penelitian ini dilakukan data saling terkait terus menerus, selama penelitian dilihat juga permasalahan apa yang ditemui pada pengurus kelompok tani, dinas terkait penyelengaraan program PUAP ini, sehingga hasil penelitian bisa memberikan rekomendasi kebijakan untuk perbaikan program PUAP selanjutnya.

Varibel yang diamati;

1. Program PUAP adalah program yang dilaksanakan oleh anggota kelompok tani di Kel.Rejosari Kec.Tenayan Raya

2. GAPOKTAN adalah gabungan anggota kelompok tani

3. Anggota Gapoktan adalah petani yang menjadi anggota gabungan kelompok tani

4. Pendapatan adalah penerimaan dikurangi biaya usaha yang dilakukan dari sumber dana PUAP.

5. Meningkatnya pendapatan petani penerima dana PUAP .sesuai potensi yang ada di daerah.

\section{HASIL DAN PEMBAHASAN}

Kelurahan Rejosari terletak di Kecamatan Tenayan Raya jarak 15 km dari kota Pekanbaru. Di Kelurahan Rejosari sudah ada GAPOKTAN terdiri dari 3 kelompok tani yaitu: Indah Sari,Segar Indah, Rejosari Indah. Semua anggota kelompok 43 orang, anggota yang mempergunakan dana sampai tahun 2015 ada 31 orang. PUAP di Kelurahan Rejosari dimulai tahun 2011 dengan dana awal

12 Pengaruh Dana Pengembangan Usaha Agribisnis Perdesaan Terhadap Pendapatan Anggota Kelompok Pada Gapokatan Di Keluran Rejosari Kecamatan tenayan raya 
100.000.000 rupiah (seratus juta rupiah), dana mulai dicairkan pada bulan November 2010. Pada saat ini tahun 2015 dana sudah meningkat menjadi 181.000.000 rupiah(seratus delapan puluh satu juta rupiah). Disini sudah ada koperasi dengan nama Rejosari Indah sampai sekarang sudah ada warung harian untuk memenuhi kebutuhan anggota koperasi dan masyarakat sekitar . GAPOKTAN Rejosari Indah ini merupakan juara I lomba pada tahun 2015 kota Pekanbaru, dan juara 2 di Provinsi Riau. Merupakan GAPOKTAN yang sukses untuk kota Pekanbaru dan Propinsi Riau.

Tabel 1 : Karakteristik Identitas Reponden Anggota Gapoktan

\begin{tabular}{|c|c|c|c|}
\hline \multirow{3}{*}{$\begin{array}{l}\mathrm{NO} \\
1\end{array}$} & Identitas Respoden & Jumlah (orang) & $(\%)$ \\
\hline & $\begin{array}{l}\text { Jenis Kelamin } \\
\text { Wanita } \\
\text { Pria }\end{array}$ & $\begin{array}{l}22 \\
0\end{array}$ & $\begin{array}{l}100 \\
-\end{array}$ \\
\hline & Jumlah & 22 & 100 \\
\hline \multirow[t]{2}{*}{2} & $\begin{array}{ll}\text { Umur } & \\
\text { a. } & 25-35 \\
\text { b. } & 36-44 \\
\text { c. } & 45-54 \\
\text { d. } & 55-64 \\
\end{array}$ & $\begin{array}{l}3 \\
11 \\
6 \\
2 \\
\end{array}$ & $\begin{array}{l}13,65 \\
50 \\
27,26 \\
9,09\end{array}$ \\
\hline & Jumlah & 22 & 100 \\
\hline \multirow[t]{2}{*}{3} & \begin{tabular}{ll}
\multicolumn{2}{l}{ Pendidikan } \\
a. & SD \\
b. & SLP \\
c. & SLA
\end{tabular} & $\begin{array}{l}12 \\
4 \\
6 \\
\end{array}$ & $\begin{array}{l}54,54 \\
18,19 \\
27,27 \\
\end{array}$ \\
\hline & Jumlah & 22 & 100 \\
\hline \multirow[t]{2}{*}{3} & 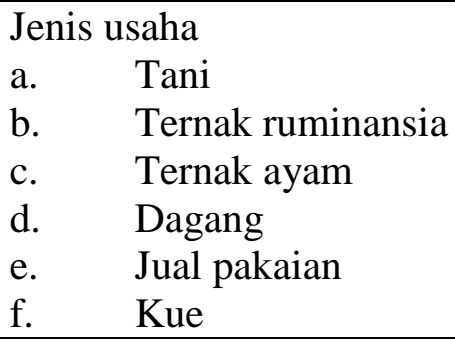 & $\begin{array}{l}7 \\
3 \\
2 \\
5 \\
1 \\
4\end{array}$ & $\begin{array}{l}31,82 \\
13,64 \\
9,09 \\
22,72 \\
4,5 \\
18,19 \\
\end{array}$ \\
\hline & Jumlah & 22 & 100 \\
\hline
\end{tabular}

Berdasarkan data pada tabel di atas yang menjadi responden dalam penelitian jenis kelamin semua wanita karena anggota kelompok tani semua wanita.Wanita pada GAPOKTAN Rejosari Indah ini melakukan semua kegiatan usaha . Rataan umur responden 30 -54 tahun (90.91\%) berada pada usia produktif ,2 orang diatas 55 tahun $(9,09 \%)$. Di tinjau dari segi umur semakin tua maka semakin baik mengelola usahataninya. Dengan demikian pada usia produktif semakin menunjang usaha akan meningkatkan hasil usaha ,pada akhirnya dapat meningkatkan pendapatan petani dan akan lebih mudah untuk mengembalikan 
dana pinjaman usaha. Disisi lain semakin bertambah umur akan menurun fisiknya dan memerlukan bantuan tenaga kerja keluarga dan luar keluarga (Ken Suratyah,2006).

Tingkat pendidikan paling banyak Sekolah Dasar 12 orang $(54,54 \%)$ karena pada umumnya petani yang datang dari jawa ke Pekanbaru tanpa keahlian khusus.Tingkat pendidikan akan mempengaruhi pola usaha tani tetapi responden ini dalam melakukan usaha sangat antusias menerima pelatihan dan workshop yang di lakukan oleh PPL selalu diadakan setiap bulan ,sehingga ilmu dapat diterima dan diterapkan .

Dari hasil penelitian ada 6 jenis usaha yang dilakukan responden dari dana PUAP yaitu:

a. Melakukan usaha tani

b. Ternak ruminansia (Kambing)

c. Ternak ayam dan jual ayam

d. Dagang

e. Usaha kue

f. Jual pakaian.

Dari ke enam usaha yang memperoleh dana PUAP paling banyak ( 7 orang atau $31,82 \%$ ) melakukan usaha tani berupa tanaman singkong,cabe, terung,slada ,dan lain-lain. Kedua melakukan usaha dagang sebanyak 5 orang $(22,72 \%)$ berupa warung harian, makanan ringan,sayuran . Ketiga melakukan usaha kue sebanyak 4 orang $(18,19 \%)$ berupa kue basah dan kue kering. Selanjutnya ternak kambing.

Bidang usaha yang dilaksanakan oleh GAPOKTAN Rejosari Indah sesuai bidangnya yaitu;

a. Bidang Peternakan; pemeliharaan ternak sapi, ternak kambing,ayam kampung, ayam potong dan itik.

b. Bidang Pertanian ; Palawija ( ubi kayu,jagung), Hortikultura ; terung ,sawi, cabe rawit, rimbang,kemangi,dll. Buah-buahan ; pisang, pepaya. Dan bumbu dapur.

c. pengolahan hasil pertanian ; kue basah, keripik cabe, warung harian, warung sarapan pagi dan gorengan. 
Menurut Darius (2010) menyatakan kegiatan usaha agribisnis ada empat subsistem yaitu; 1. Sub sistem agribisnis hulu. 2. Sub sistem produksi tani .3. sub sistem agribisnis hilir .4. sistem lembaga penunjang.

1. Sub sistem agribisnis hulu yaitu kegiatan ekonomi yang menyediakan sarana produksi bagi pertanian seperti pupuk, pestisida,mesin, peralatan atau benih, bibit. Perusahaan agribisnis hulu dapat melakukan pelayanan melalui pelayanan pelayanan bermutu pada usahatani, memberikan bimbingan teknis produksi ,memberikan bimbingan manajemen dan hubungan agribisnis ,memfasilitasi pembelajaran pelatihan bagi petani ,memberi dan menjaring informasi agribisnis praktis untuk serta mengembangkan kerja bisnis (kemitraan).

2. Sub sistem produksi tani seperti kegiatan ekonomi mengunakan sarana produksi mengunakan sub sistem agribisnis hulu untuk menghasilkan produk pertanian primer seperti; usaha tanaman pangan,tanaman hortikultra, usaha tanaman obat-obatan. Usaha tanaman perkebunan, perikanan, peternakan, kehutanan. Sub sistem usaha tani sebagai produsen pertanian berfungsi melakukan tekhnis produksi agar produksinya dipertanggung jawabkan baik kualitas maupun kuantitas.

3. Sub sistem agribisnis hilir merupakan kegiatan ekonomi yang mengolah produk pertanian primer menjadi produk olahan ,beserta kegiatan perdagangan di pasar domestik maupun di pasar internasional. Kegiatan ekonomi yang termasuk sub sistem agribisnis hilir antara lain industri pengolahan makanan ,industri pengolahan serat (kayu, kulit, karet, jerami, sutera) industri jasa, industri farmasi dan bahan kecantikan . Sub subsistem perusahaan agribisnis hilir berungsi melakukan pengolahan lebih lanjut (baik primer, sekunder, tertier) untuk mengurangi susut nilai dan untuk meningkatkan mutu produk agar dapat memenuhi kebutuhan dan selera konsumen ,serta memperlancar pemasaran melalui perencanaan sistem pemasaran yang baik.

4. Sistem lembaga penunjang merupakan seluruh kegiatan menyediakan jasa agribisnis seperti ; lembaga keuangan, lembaga penelitian dan pengembangan, jasa transportasi, lembaga pendidikan, pemerintah 
(kebijakan fiskal, moneter, perdagangan internasional serta kebijakan tata ruang ).

Hasil penelitian menunjukan pendapatan responden yang memperoleh dana PUAP rata-rata Rp 636,364,- perbulan ,ini dibawah UMR kota Pekanbaru sebesar Rp 1.750.000,- per bulan. Walaupun pendapatan masih rendah responden telah dapat meningkatan pendapatan rumah tangga setiap bulannya. Dengan adanya dana ini telah menambah peningkatan pendapatan anggota kelompok tani di kelurahan Rejosari. Peningkatan Pendapatan menurut Suwajono (2005) ,mengungkapkan bahwa pendapatan tergantung pada modal yang dimiliki. jika modal besar maka produksi tinggi sehingga pendapatan juga akan tinggi dan sebaliknya jika modal kecil maka produksi juga sedikit maka pendapatan juga rendah. Dari teori tersebut maodal akan menentukan pendapatan.

Hasil penelitian ini dana bantuan PUAP telah dapat meningkatkan pendapatan keluarga ,melalui usahatani petani telah memperoleh pendapatan untuk rumah tangga mereka .selama dana digulirkan telah membuat penerima dana telah melakukan usaha dan meningkat setiap tahunnya. Hasil penelitian ini sesuai dengan penelitian Mariah(2009) dan Endang Yuni Hastuti (2008) bahwa bantuan dana akan berpengaruh positif dan nyata peningkatan produksi dan peningkatan pendapatan petani. Dengan adanya dana maka seseorang akan bergairah untuk memperbesar usahanya ,pemberian dana akan menambah modal kerja.

Hasil penelitian Erna K,dkk , (2012) menyatakan bahwa jenis usaha yang dilakukan perdagangan ,rata-rata pendapatan $\mathrm{Rp} 768.000,-$,dana PUAP berpengaruh terhadap pendapatan .

Pada penelitian ini telah ada peningkatan pendapatan pada anggota GAPOKTAN berarti dana bantuan telah menambah pendapatan walaupun masih dibawah UMR ,penerima dana sudah merasa terbantu dengan bantuan ini dan telah berdampak positif terhadap anggota kelompok .

Dengan adanya dana PUAP ini responden telah melakukan usaha dengan 6 jenis yang memberikan penambahan pendapatan keluarga serta sudah dapat membantu kegiatan anggota koperasi .Selama perjalanan dana PUAP di gulirkan di Kelurahan Rejosari telah menumbuhkan wirausaha baru berawal dari pinjaman Rp 3.000.000,- dengan perputaran uang lancar sekarang sudah dapat pinjaman 
Rp 5.000.000,- bahkan dapat pinjaman sampai Rp 10.000.000,- per anggota dari yang sebelumnya tidak memiliki usaha sekarang sudah memiliki usaha . Jadi telah terjadi peningkatan jumlah modal usaha agribisnis selama ini sudah berjalan baik dan dapat terus digulirkan bagi anggota kelompok sehingga memberi pengaruh positif pada pendapatan rumah tangga, sudah membuat lapangan pekerjaan untuk ibu -ibu anggota Kelompoknya. Usaha yang dilakukan sudah melalui proses yang dilalui akan meningkatkan keberhasilan.

Dana PUAP memang diberikan pada setiap Kelurahan ,pada Kelurahan Rejosari ini telah terjadi pengaruh dana terhadap masyarakat terutama anggota kelompok tani yang bergabung menjadi GAPOKTAN,sebelum adanya dana ini anggota kelompok belum banyak melakukan usaha karena ketiadaan modal sakarang sudah hampir semua anggota telah melakukan usaha.

\section{KESIMPULAN DAN SARAN}

\section{Kesimpulan}

Dari hasil peneitian ini dapat disimpulkan;

1. Jenis usaha yang di danai PUAP adalah; Melakukan usaha tani ,Ternak ruminansia (Kambing),Ternak ayam dan jual ayam,Dagang ,Usaha kue,Jual pakaian.

2. Pendapatan bersih dari usaha sumber dana PUAP rata-rata sebesar Rp 636,364,- perbulan .

3. Pengaruh pemberian dana PUAP terhadap anggota kelompok sudah dapat memberikan lapangan pekerjaan , menambah pendapatan keluarga.

\section{Saran}

1. Jumlah dana yang diberikan dapat ditingkatkan untuk menambah modal usaha.

2. Perlu pelatihann dan pendampingan dari instansi terkait untuk meningkatkan produktivitas.

\section{DAFTAR PUSTAKA}

Antara ,Made. 2010. Sistem Agribisnis .Bahan Ajar Program Magister Agribisnis .Program Pasca Sarjana Universitas Udayana.Denpasar.

Darius , 2010. Sub Sistem Agribisnis. Tersedia pada http ://agrimaniax blokspot.com 2010/2006/subsistem agribisnis.html. 
Departemen Pertanian, 2007. Peraturan Menteri Pertanian . no .273/Kpts/OT.160/4/2007,tanggal 13 April 2007 tentang Pedoman Penumbuhan dan Pengembangan Kelompok tani dan Gabungan Kelompoktani .Departemen Pertanian.Jakarta.

,2008. Petunjuk Teknis Penyaluran Dana BLM -PUAP. Departemen Pertanian .Jakarta.

2009. Petunjuk Teknis Verifikasi Dokumen Pengembangan Usaha Agribisnis Pedesaan(PUAP) .Jakarta .Departemen Pertanian Presss.

Erna, K.I Ketut Kirya,Ni Nyoman Ylianthini, 2012.Pengaruh Dana Pengembangan Usaha Agribisnis Perdesaan Terhadap Pendapatan Anggota Kelompok SIMANTRI.

Hastuti,2008. Pengaruh Penerapan Sistem Agribisnis Terhadap Peningkatan Petani Sayur di Boyolali.

Mariah, 2009. Pengaruh Bantuan Pinjaman Langsung Masyarakat Terhadap Pendapatan dan Efisiensi Usaha Padi Sawah di Kabupaten Penajen Paser.

Suwardjono, 2005. Teori Akuntansi Perekayasaan Pelaporan Keuangan. Edisi 3 .BPFE, Jogyakarta. 